\title{
A Rhizobium meliloti homolog of the Escherichia coli peptide-antibiotic transport protein SbmA is essential for bacteroid development
}

\author{
Jane Glazebrook, ${ }^{1}$ Asao Ichige, and Graham C. Walker \\ Department of Biology, Massachusettts Institute of Technology, Cambridge, Massachusetts 02139 USA
}

\begin{abstract}
Alfalfa nodules induced by a Rhizobium meliloti strain carrying the bacA386::TnphoA mutation (formerly fix386::TnphoA) were examined by light and electron microscopy. These ineffective nodules were found to contain bacteria within infection threads, but no mature bacteroids were observed. A closer examination revealed that there were undeveloped senescent bacteroids in the plant cells of the nodule invasion zone, strongly suggesting that the symbiotic defect of the bacA386::TnphoA mutant is attributable to an early block in bacteroid development. The expression of the bacA gene in effective nodules was monitored with a $b a c A-p h o A$ fusion and found to be strongest in the region where developing bacteroids are found. The $b_{a c A}{ }^{+}$ gene was cloned and sequenced. Sequence analysis indicated that BacA is probably an integral inner membrane protein with seven transmembrane domains and that it is extremely homologous to Escherichia coli $\operatorname{SbmA}$, an inner membrane protein required for the uptake of microcin B17, a peptide antibiotic. Southern blotting experiments indicate that a gene closely related to $b a c A / s b m A$ is found in many bacteria, including some that invade eukaryotic cells. Possible roles for BacA in symbiosis are discussed.
\end{abstract}

[Key Words: BacA; bacteroids; SbmA; R. meliloti; nodule development]

Received March 29, 1993; revised version accepted May 26, 1993.

Gram-negative bacteria of the genus Rhizobium fix nitrogen in symbiotic association with leguminous plants. The development of this interaction proceeds through several stages. It commences with curling of a root hair, trapping the rhizobia in the curl. At the same time, a meristem forms within the root and begins to grow outward, forming a nodule. The bacteria invade the developing nodule through a tube called an infection thread, which originates at the tip of the root hair and grows through the root hair and into the developing nodule, where it branches and penetrates many of the nodule cells. The bacteria are released from the tips of the infection threads into the plant cells through a poorly understood mechanism similar to endocytosis, becoming enclosed in membranes of plant origin, called peribacteroid membranes. Within these membranes, the intracellular bacteria, termed bacteroids, enlarge and differentiate into their mature form, whereupon nitrogen fixation begins.

Alfalfa nodules are indeterminate, meaning that the nodule meristem continues to grow outward, giving rise to cells that are in turn infected by rhizobia throughout

${ }^{1}$ Present address: Department of Molecular Biology, Massachusetts General Hospital, Boston, Massachusetts, 02114. the course of nodule development. The ultrastructure of alfalfa nodules induced by Rhizobium meliloti has been described in great detail (Jordan et al. 1963; Tu 1977; Paau et al. 1980; Patel and Yang 1981; Hirsch et al. 1983; Vasse et al. 1990). The meristem (zone I) consists of small, rapidly dividing cells. It is followed by the infection zone (zone II), in which many of the host cells are penetrated by infection threads. At the tips of the threads, near the host cell nuclei, the bacteria are released into the plant cells. The released bacteria are referred to as type I bacteroids. The root-proximal cells of the infection zone contain bacteroids that have begun to differentiate. These type II bacteroids are larger, more elongate, and appear less electron-dense in electron micrographs than type I bacteroids. Zone II is followed by a narrow band of cells called the zone II-III interzone. These cells are rich in starch granules and contain bacteroids that have developed to the type III stage. They are similar in size and shape to the type II bacteroids, but their cytoplasm is heterogeneous, containing regions of high and low electron density. The next oldest cells comprise the symbiotic zone (zone III). These cells have large central vacuoles, and their cytoplasm is packed with mature, nitrogen-fixing type IV bacteroids, which are characterized by bands of high and low electron density in 
their cytoplasm. Older nodules include a senescent zone IV proximal to the root, consisting of senescing host cells that contain senescent type $\mathrm{V}$ bacteroids (Vasse et al. 1990).

The analysis of bacterial mutants that are arrested at various stages has been a powerful approach to studying the development of these nodules, in part attributable to the well-developed system for genetic manipulation of R. meliloti (Glazebrook and Walker 1991). Bacterial genes that are required for early and late events in nodule development have been studied intensively. Consequently, the key roles played by the bacterial nod genes in initiating the symbiosis are now fairly well understood (Fisher and Long 1992). The expression of these genes is induced in response to flavonoid compounds exuded by the host plant and results in elaboration of lipo-oligosaccharides that cause root hair deformation (Had) and elicit the formation of nodule-like structures (Rolfe and Gresshoff 1988; Long 1989a,b). Similarly, the functions of a number of genes expressed by mature nitrogen-fixing bacteroids in fully developed nodules have been established. These include the nif genes, which encode nitrogenase, the enzyme that reduces molecular nitrogen to ammonia, and several fix loci, which encode enzymes involved in electron transport as well as regulatory proteins (Long 1989a).

Relatively little is known about the bacterial functions required for intermediate events in nodule development. Several classes of mutants blocked early in nodule invasion have been isolated. These include exo mutants, which have defects in exopolysaccharide biosynthesis (Finan et al. 1985; Leigh et al. 1985, 1987; Keller et al. 1988; Long et al. 1988b), $n d v A$ and $n d v B$ mutants, which have defects in the synthesis and transport of cyclic $\beta-(1,2)$ glucan (Dylan et al. 1986; Geremia et al. 1987), ndvF mutants (Charles et al. 1991), as well as exoD mutants, whose symbiotic deficiency seems to be attributable to sensitivity to alkaline $\mathrm{pH}$ (Reed and Walker 1991). The nodules induced by all of these mutants are small, round, and generally devoid of bacteria. Infection threads, if present at all, generally terminate in the nodule cortex (Finan et al. 1985; Dylan et al. 1986; Leigh et al. 1987). There are also reports of $R$. meliloti mutants that are retained within infection threads. Some leucine auxotrophs invade nodules but are not then released from infection threads (Truchet et al. 1980), whereas bacteria carrying mutations in hem $A$ undergo senescence within enlarged infection threads and are not released into the plant cell cytoplasm (Dickstein et al. 1991). Clearly, there must be other bacterial functions required for the complex processes of nodule invasion and bacteroid development that have not yet been identified.

A set of symbiotically defective mutants isolated in this laboratory may include some that induce nodules arrested at intermediate stages in development. These mutants share the common features of containing insertions of the transposon TnphoA that cause alkaline phosphatase expression [indicating that they synthesize a fusion protein that is exported out of the cytoplasm
[Manoil and Beckwith 1985)] and inducing ineffective nodules on alfalfa (Long et al. 1988b). In this paper we present our finding that strains carrying one of these mutations, fix386::TnphoA induce nodules that display a novel developmental phenotype. We also describe the pattern of expression of the fusion protein generated by the fix 386::TnphoA insertion in nodules, and the cloning and sequencing of the gene defined by this mutation. As a consequence of our analysis, we have renamed the fix386::TnphoA mutation bacA386::TnphoA, for bacteroid development.

\section{Results}

The bacA386::TnphoA mutant induces nodules that are devoid of mature bacteroids

The nodules induced by the bacA386::TnphoA strain, which varied in size, were cylindrical, white in color, and did not fix nitrogen (Long et al. 1988a). They were smaller than the cylindrical, pink, effective nodules induced by the corresponding $b a c A^{+}$strain, but generally larger than the round, white nodules induced by exo mutants. These characteristics suggested that nodules induced by the bacA386::TnphoA mutant were blocked at an intermediate stage in development and led us to examine them by using light microscopy.

A longitudinal section through a nodule induced by the bacA386::TnphoA mutant strain is shown in Figure 1. The early developmental zones in this nodule are similar to those of effective nodules. There is a meristem (zone I) at the nodule apex, although this is somewhat smaller than those of effective nodules. The section shown in Figure 1 was cut at a slight angle to the longitudinal axis; therefore, part of the meristem is not included. Below the meristem there is an infection zone (zone II) consisting of plant cells with central nuclei and numerous small vacuoles in their cytoplasm. Many of these cells are penetrated by infection threads containing bacteria.

The rest of the nodule induced by the $b a c A$ mutant differs from effective nodules. In effective nodules, zone II is followed by the symbiotic zone III, in which the plant cells are packed with mature, nitrogen-fixing bacteroids. In contrast, in the nodule induced by the bacA386::TnphoA mutant, zone II is followed by a wide band of cells containing no bacteroids, little cytoplasm, and large numbers of starch granules. Accumulation of starch granules has been observed in a variety of ineffective nodules (Pankhurst 1974; Truchet et al. 1980; Werner et al. 1980; Finan et al. 1985). The nodule cells proximal to the root appeared senescent and did not contain any bacteroids. The nodule shown in Figure 1 is of average size for one induced by the bacA386::TnphoA mutant. Larger nodules were similar in appearance to the one shown but contained more senescent cells. From these observations, we concluded that the bacA386::TnphoA mutant successfully penetrated the nodule cells within infection threads but failed to differentiate into bacteroids. 


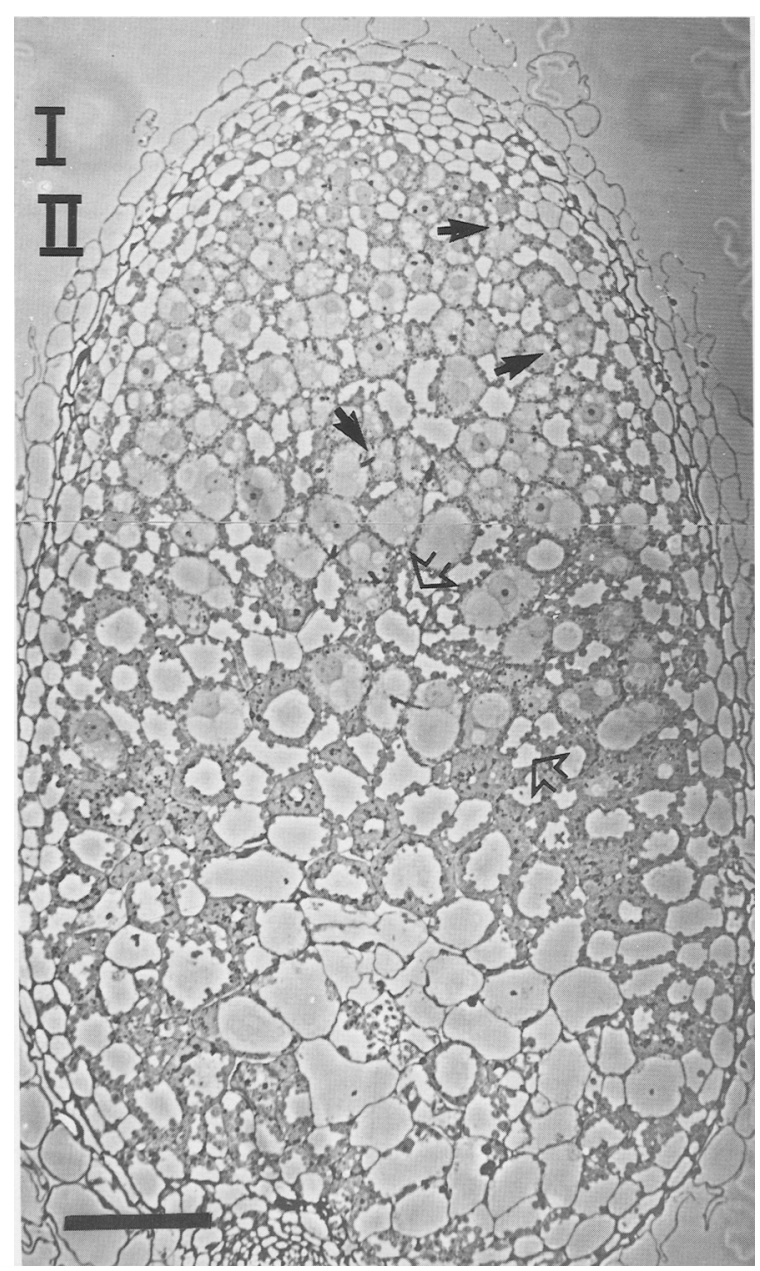

Figure 1. Longitudinal sections of a nodule induced by strain Rm8386 (pho-1 bacA386::TnphoA). (I) Meristem zone I; (II) infection zone II; (solid arrows) infection threads; (open arrows) cells containing starch granules. Bar, $100 \mu \mathrm{m}$.

\section{bacA bacteria undergo senescence shortly after their release into plant cells}

We used electron microscopy to determine whether the defect in development of $b a c A$-induced nodules was the result of retention of the bacteria within the infection threads, as in the case of hemA mutants (Dickstein et al. 1991), or from the failure of the bacteria to differentiate into bacteroids after their release from the infection threads. We examined the infection zone II in wild-type and bacA nodules, as bacterial release from infection threads and the first steps of bacteroid development occur in this zone. Figure 2 shows sections from wild-type and $b a c A$-induced nodules. Figure $2 \mathrm{~A}$ shows a cell in a wild-type nodule that is penetrated by an infection thread, with bacteria being released into the cytoplasm near the nucleus. The bacteria within the infection thread contain electron-transparent granules of poly- $\beta$ hydroxybutyrate and are surrounded by infection thread matrix material (Tu 1977; Paau et al. 1978). Over most of its length, the infection thread has a wall that is contin- uous with the host cell wall and separated from the cytoplasm by the infection thread membrane, which is continuous with the plasma membrane. At the tip of an infection thread, this wall is absent, allowing the bacteria to come into direct contact with the infection thread membrane. They exit the infection thread in a process resembling endocytosis, becoming enclosed in a plantderived membrane, termed the peribacteroid membrane (Newcomb 1981). In Figure 2A, the presence of infection thread matrix material $(\mathrm{m})$ in the cluster of bacteria near the nucleus indicates that these bacteria (arrowheads) are within the unwalled tip of an infection thread. Bacteria that have been released from the infection thread (termed type I bacteroids) are present in the cytoplasm nearby (arrows).

Figure 2B shows a cell from a bacA nodule that is penetrated by an infection thread. This cell is similar to the one shown in Figure 2A in that the tip of the infection thread is near the nucleus and contains bacteria (arrowhead) surrounded by infection thread matrix material (m). Released bacteroids are present in the cytoplasm nearby (arrows). However, the released bacteroids in the vicinity of the infection thread tips appeared to be somewhat smaller, more intensely stained, and irregularly shaped compared with the wild-type bacteroids shown in Figure 2A. Evidently, bacA bacteria are released from infection threads but are defective at some later step in development. To ascertain the nature of this defect, we examined developing bacteroids from wild-type and bac $A$-induced nodules.

Type I and type II developing bacteroids from the invasion zone II of a wild-type nodule are shown in Figures 3 , A and B, respectively. Type I bacteroids are similar in size to free-living bacteria, the cytoplasm shows uneven staining, poly- $\beta$-hydroxybutyrate granules are generally absent (Hirsch et al. 1982), and the peribacteroid space is relatively large. Type II bacteroids have begun to elongate, the cytoplasm is stained more uniformly, and the peribacteroid space has become smaller.

No structures resembling type I or type II bacteroids were observed in the invasion zones II in $b a c A$-induced nodules. Rather, $b a c A$ bacteroids were very intensely stained and irregularly shaped, indicating that they were senescent (Fig. 3C-F). Frequently, they were roughly spherical, with a long narrow protuberance (Fig. 3C-E). Many of the senescent bacteroids contained poly- $\beta$-hydroxybutyrate granules (Fig. 3D,F). The presence of these granules suggests that $b a c A$ bacteroids undergo senescence soon after exiting from the infection thread, as loss of poly- $\beta$-hydroxybutyrate occurs rapidly after release of wild-type bacteroids from infection threads (Paau et al. 1978, 1980; Hirsch et al. 1982). This idea is supported by the observation that clearly senescent bacteroids were often observed in host cells that also contained infection thread tips from which bacteroids were being released (the bacteroids shown in Fig. 3C were found in such a cell). The senescent bacteroids in the root-proximal (older) cells of the invasion zone appeared more extensively degraded than those found in the root-distal (younger) cells. From this analysis we concluded that the 
Figure 2. $\langle A|$. An infection thread in the infection zone of a nodule induced by the bacA ${ }^{+}$parent strain $\mathrm{Rm} 8002$. (B) An infection thread in the infection zone of a nodule elicited by the bacA386::TnphoA strain Rm8002. (N) Host cell nucleus; (W) host cell wall; $(I)$ walled infection threads containing bacteria surrounded by infection thread matrix material $(\mathrm{m})$. The presence of infection thread matrix material defines unwalled tips of infection threads containing bacteria (arrowheads). Small solid arrows point to bacteria that have entered the host cytoplasm; large open arrows indicate amorphous dark-staining objects in $B$. Bars, $1 \mu \mathrm{m}$.
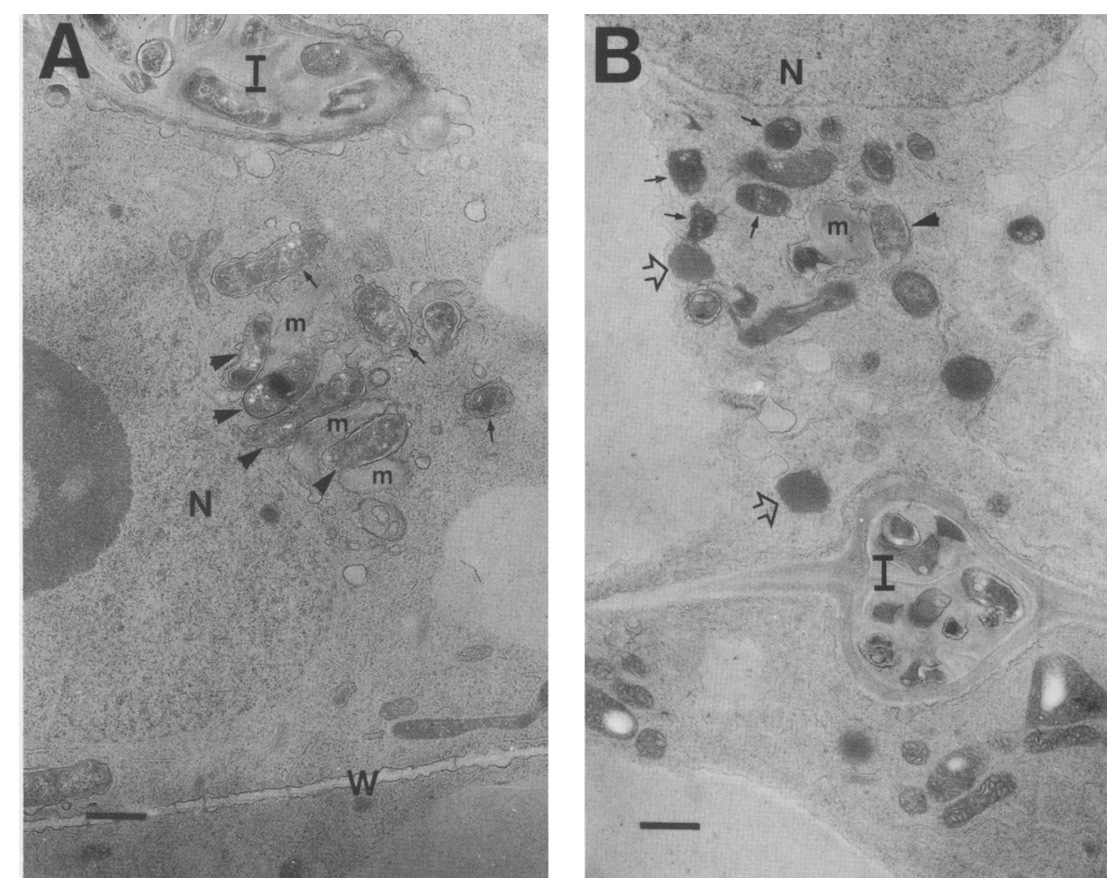

development of $b a c A$ nodules is blocked at the onset of bacteroid development, as the bacteria are clearly released from infection threads but undergo senescence immediately thereafter, as evidenced by the lack of type I bacteroids and the presence of poly- $\beta$-hydroxybutyrate granules in the senescent bacteroids.

Another unusual feature of the $b a c A$ nodule zone II cells was the presence of amorphous, darkly stained objects in the infected cells (Figs. 2B and 3F). These objects appear to be heavily and uniformly stained with osmium, suggesting that they are aggregations of lipids. These structures were not observed in wild-type nodules.

\section{Cloning of the bacA gene}

Our approach to cloning the $b a c A$ gene took advantage of the fact that the bacA386 mutation was marked by a TnphoA insertion. We cloned a fragment of DNA from the bacA386::TnphoA strain that included the neomycin phosphotransferase gene of the transposon and genomic sequences flanking one side of the insertion. This plasmid was used to probe a genomic library of $R$. meliloti DNA. Three different cosmids containing overlapping inserts were identified and named pJG50, pJG60, and pJG70 (Fig. 4).

These three cosmids were transferred into the bacA386::TnphoA strain by conjugation, and the resulting strains were found to induce effective nodules on alfalfa, indicating that sequences on these cosmids are capable of complementing the bacA386::TnphoA mutation. To confirm that this was true complementation rather than suppression, we performed Southern hybridizations using pJG50 as a probe and showed that the
TnphoA insertion in the bacA386::TnphoA mutant is in a $3.0-\mathrm{kb} B a m H I$ fragment that is carried by all three cosmids (Fig. 4). This BamHI fragment was subcloned into pRK404 to create pJG51 (Fig. 4). pJG51 also complemented the symbiotic defect caused by the bacA386::TnphoA mutation. Taken together, these experiments showed that the $3.0-\mathrm{kb} B a m H I$ fragment of pJG50 contains the $b a c A^{+}$gene. Furthermore, the fact that the bacA386::TnphoA mutation is recessive to the $b a c A^{+}$allele argues that the phenotype of the $b a c A \mathrm{mu}-$ tant results from loss of function of the $b a c A^{+}$gene, rather than from a deleterious effect of the fusion protein encoded by the bacA386:: $\operatorname{Tn} p h o A$ allele.

\section{Transposon mutagenesis of the bacA $^{+}$cosmids p/G50 and $p / G 70$}

Many R. meliloti genes (nod, exo, and nif) that are required for effective nodulation are organized in large gene clusters. To determine whether $b a c A$ was part of such a cluster, we mutagenized the $b a c A^{+}$cosmids pJG50 and pJG70 with the transposon Tn3Gus. We chose 33 insertions that were fairly evenly spaced along the length of the cosmid inserts and introduced them into the corresponding positions in the R. meliloti genome by homogenotization. The resulting Tn3Gus insertion mutants were then tested for nodulation effectiveness. None of the insertions except 84 (discussed below) caused any symbiotic defects. Thus, it does not appear that the bacA gene lies in a large cluster of symbiotic genes, although we cannot exclude the possibility that pJG50 carries a small symbiotic locus that was not interrupted by any of the Tn3Gus insertions in our collection. 


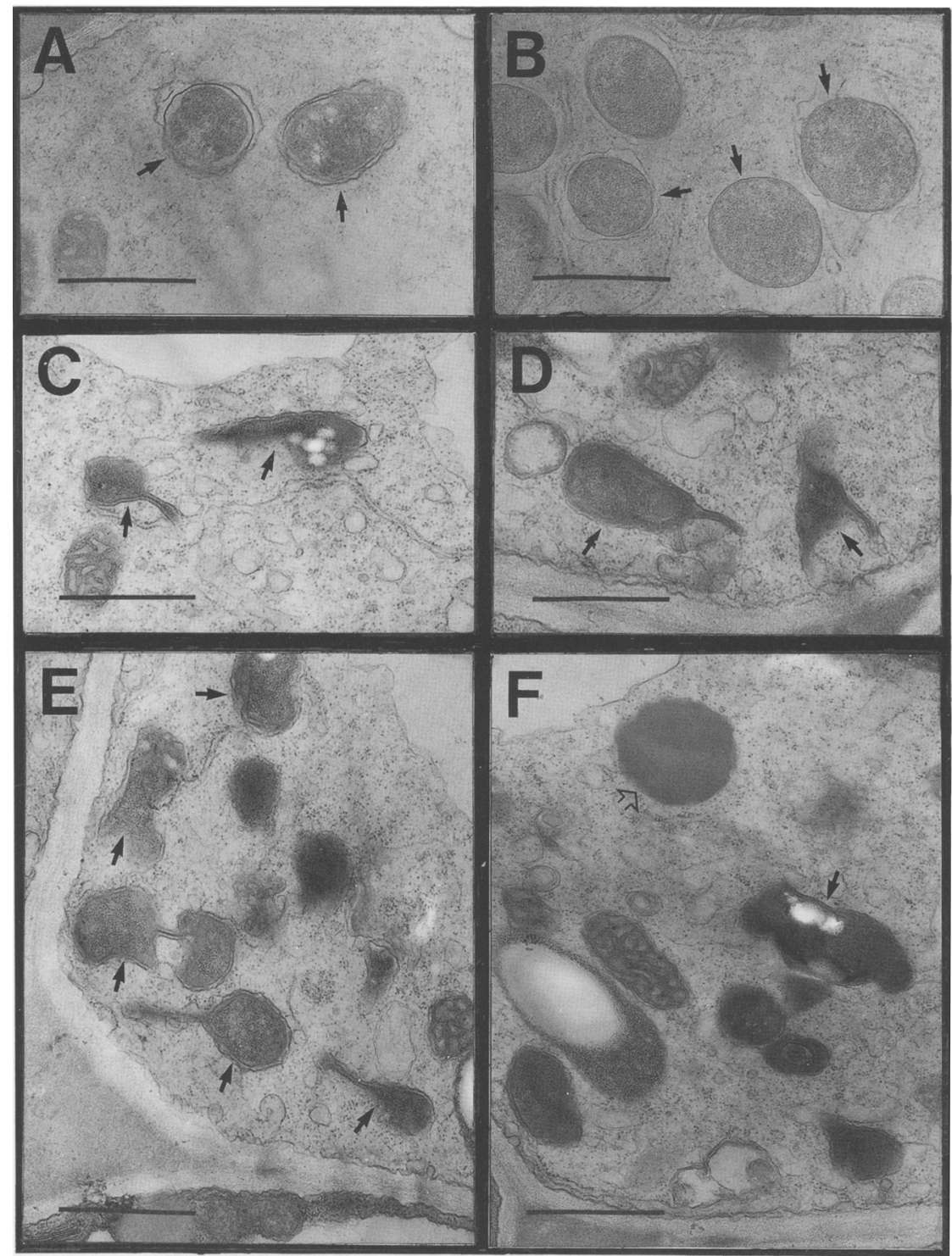

Figure 3. (A) Type I bacteroids in the rootdistal portion of the infection zone II of a nodule induced by the $b a c A^{+}$strain Rm8002. (B) Type II bacteroids from the root-proximal portion of the infection zone II of the same nodule shown in $A$. $(C-F)$ Senescent bacteroids (indicated by small solid arrows) found in the infection zone II of nodules elicited by the bacA386::TnphoA strain $\mathrm{Rm} 8386$. The unstained structures within the right-hand bacteroid in $C$ and the bacteroid in $F$ are granules of poly- $\beta$ hydroxybutyrate. The large open arrow in $F$ points to an amorphous dark-staining object. Bars, $1 \mu \mathrm{m}$.
We also used this set of mutagenized cosmids to delimit further the $b a c A$ gene. The seven cosmids that had insertions in the $3.0-\mathrm{kb}$ BamHI fragment that contains $\mathrm{bacA}^{+}$(Fig. 4) were tested for their ability to complement the bacA386::TnphoA mutation and thereby allow effective nodule formation. Only the cosmid containing insertion 84 failed to complement, demonstrating that the $\mathrm{bacA}^{+}$gene lay between the positions of insertions 70 and 58. Mutants containing insertion 84 induced ineffective nodules that were indistinguishable from those induced by the bacA386:: TnphoA strain, as judged by light microscopy. Therefore, this mutation was designated bacA84::Tn3Gus.

bacA gene expression is concentrated in the early symbiotic zone of nodules

The observation that $b a c A$ mutants were arrested early in bacteroid development led us to wonder at which stages $b a c A$ was expressed in normally developing nodules. To address this question, we took advantage of the fact that bacA386::TnphoA strains carrying the $b a c A^{+}$ plasmid pJG50 nodulate normally, and the bacterial alkaline phosphatase activity of the BacA-PhoA fusion protein can be detected in situ using a histochemical stain (Reuber et al. 1991). Alfalfa plants were inoculated with a Pho- ${ }^{-}$strain, a bacA386::TnphoA derivative containing the $b a c A^{+}$cosmid, pJG50, or a dctA384::TnphoA derivative containing the $\operatorname{dct} A^{+}$cosmid, pTF8 [the $\operatorname{dct} A$ gene is required for succinate transport, a physiological activity that is needed to support nitrogen fixation (Bolton et al. 1986), and was included as a positive control]. The effective nodules induced by these bacteria were excised from roots 19 days postinoculation, sectioned, and stained for alkaline phosphatase activity. Although the resolution in these thick sections was insufficient to make an accurate determination of the location of the various developmental zones, we estimated which of the 


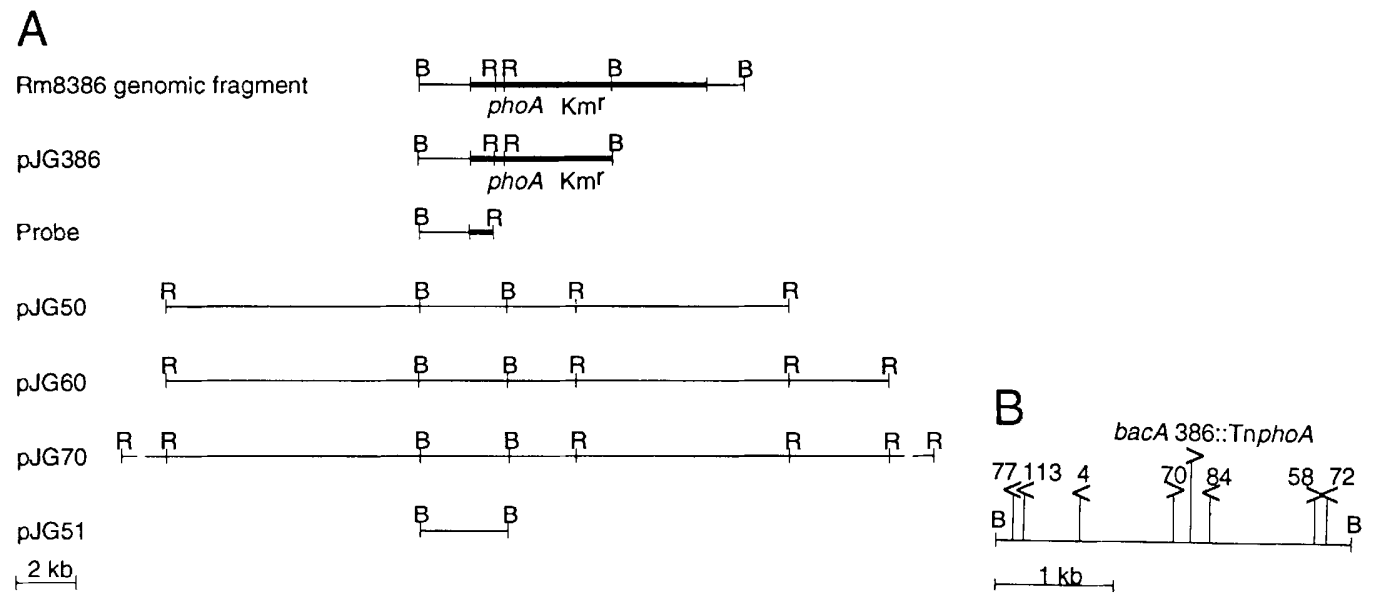

Figure 4. $(A)$ R. meliloti DNA derived from the bacA locus that is present in various plasmids. pJG50, pJG60, and pJG70 are derivatives of the IncP cosmid vector pLAFR1 (Friedman et al. 1982), whereas pJG51 is a derivative of the IncP vector pRK404 (Ditta et al. 1985). (B) BamHI restriction site $;(R) E c o R I$ restriction site. Thick lines indicate TnphoA sequences; thin lines indicate $R$. meliloti sequences. The broken line in the pJG70 restriction map indicates uncertainty in the position of the $1.7-\mathrm{kb} E c o$ RI fragment. $(B)$ Positions of Tn 3 Gus insertions in the 3 -kb region of the $R$. meliloti genome corresponding to plasmid pjG51 whose effect on symbiotic proficiency were examined. Open arrowheads indicate the orientations of the transposons; (B) BamHI sites; (R) EcoRI sites.

nodule zones were stained on the basis of the location of the symbiotic zone III, which we were able to distinguish in unstained sections. Figure 5 shows that consistent with the results of Reuber et al. (1991), nodules induced by the $\mathrm{Pho}^{-}$strain were not stained at all, although the nodules induced by the complemented $\operatorname{dct} A:: \operatorname{Tn} p h o A$

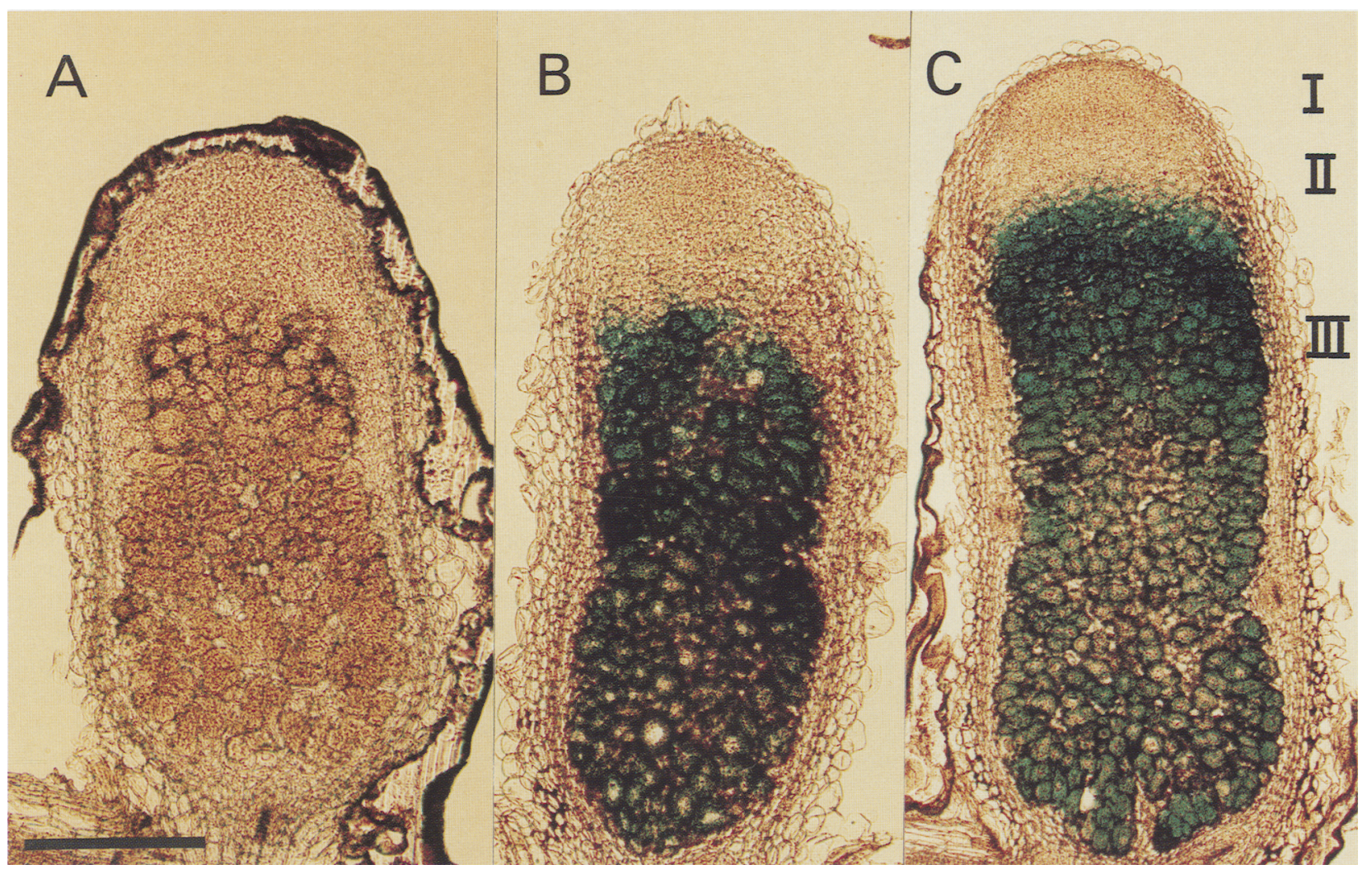

Figure 5. Longitudinal sections of nodules stained for bacterial alkaline phosphatase activity. Nodules are oriented with the apical meristem at the top. Bar, $500 \mu \mathrm{m}$. (A) Nodule induced by the pho-1 strain. (B) Nodule induced by a pho-1, dctA384::TnphoA/pTF8 $\left(d c t A^{+}\right)$strain. $(C)$ Nodule induced by a pho-1, bacA386::TnphoA/pJG50 $\left(\right.$ bacA $\left.^{+}\right)$strain. In $C$, I, II, and III indicate approximate positions of zones I (meristem), II (invasion), and III (symbiotic), respectively. 
mutant stained uniformly in the zone II-III interzone and the symbiotic zone. The nodules induced by the bacA386::TnphoA strain were stained most intensely in the proximal portion of the infection zone, the zone II-III interzone, and the root-distal portion of the symbiotic zone, whereas weaker bacA expression was observed throughout the symbiotic zone. As judged by the times required to achieve similar staining intensities in the intensely stained areas of the symbiotic zone, the level of bacA expression was roughly comparable with that of the $\operatorname{dct} A$ gene $16 \mathrm{hr}$ for bacA386::TnphoA and $16 \mathrm{hr}$ for $\operatorname{dct} A 384::$ TnphoA). Thus, it appears that the strongest expression of $b a c A$ occurs in the regions of the nodule in which bacteroid development takes place.

\section{The bacA gene encodes a highly hydrophobic protein}

We determined the nucleotide sequence of $1623 \mathrm{bp}$ from the right end of the $3-\mathrm{kb}$ insert in pJG51, which complemented the bacA386::TnphoA mutation (Fig. 6). This stretch of DNA was predicted to contain the bacA gene on the basis of the complementation experiments described previously. The correct reading frame for BacA was identified by determining the sequence of the bacATnphoA fusion junction.

This open reading frame (ORF) does not contain any AUG codons upstream from the site of the TnphoA in- sertion. However, there is a UUG codon near the beginning of the ORF that we suspect serves as an initiation codon based on the homology between BacA and Escherichia coli SbmA described below. The Agrobacterium tumefaciens VirG protein, as well as $\sim 1 \%$ of $E$. coli proteins, initiates on UUG codons; therefore, it seems reasonable that some $R$. meliloti proteins may do so also (Gren 1984; Gold and Stormo 1987; Pazour and Das 1990). Initiation at the UUG codon would result in a wild-type protein of 420 amino acids and an alkaline phosphatase fusion protein containing 47 amino acids from BacA. This is consistent with our estimate, based on Western blots, that the size of the fusion protein is 51 $\mathrm{kD}, 4 \mathrm{kD}$ larger than mature alkaline phosphatase /data not shown). The predicted BacA protein is very hydrophobic, suggesting that BacA is a membrane protein. This is consistent with previous work from this laboratory, which showed that the bacA386::TnphoA fusion protein cofractionates with cell membranes (Long et al. 1988a). The amino-terminal amino acids of BacA do not resemble a classic signal sequence (vonHeijne 1984; Benson et al. 1985). In E. coli, it is not unusual for inner membrane proteins to lack signal sequences, although they are required for transport of outer membrane proteins (Wolfe et al. 1983). Thus, on the basis of the hydrophobic nature of BacA, and its lack of a signal sequence, we predict that it is an inner membrane protein.

\footnotetext{
1 GGACAAATGAAGCTTTGGCACGATGACGGGTGCTCACTAAGCCGGGCAGGCAGCGTCGGCAGCCGCATGAAATAACAGTAACATTCGCATTCCGTAATTGTTGCGCAATGTGAATTGCCC

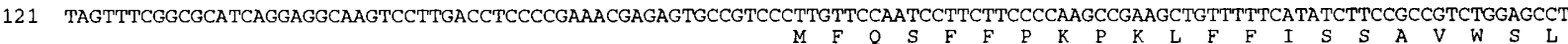
241 GCTCGCCGTCCTTGCCTGGTATGCCGGGGGGCGGGACATTGGCGCCTACCTGGGCTIGCCGCCGCTTCCTCCAGGACAGGAACCCGTCATCGGCGTGTCCGTTTTCTGGTCCACCCCTTT

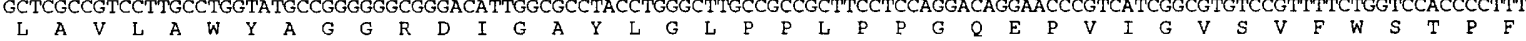

Figure 6. DNA sequence of the $b a c A^{+}$gene. The arrow indicates the position of the TnphoA insertion in the $b a c A 386::$ TnphoA strain, and the direction of translation of the alkaline phosphatase protein. Note that TnphoA insertions must be between the first and second bases of a codon for alkaline phosphatase translation to occur in-frame (Manoil and Beckwith 1985).
} 
We used the algorithm of Klein et al. (1985) to predict which segments of BacA are integral to the membrane. The first such segment is upstream from the TnphoA insertion site and probably serves to anchor the fusion protein in the membrane in an orientation that places the alkaline phosphatase moiety in the periplasmic space (cytoplasmic alkaline phosphatase is inactive). On the basis of the Klein predictions, we have proposed a hypothetical topology for BacA (Fig. 7). This model is consistent with the "positive inside" correlation of von Heijne, who observed that the cytoplasmic loops of membrane-spanning proteins tend to be charged positively, especially in prokaryotes (von Heijne and Gavel 1988).

\section{BacA is $64 \%$ identical to the peptide-antibiotic transport protein $S b m A$}

We compared the predicted BacA amino acid sequence with the GenBank data base and discovered that it is $64 \%$ identical (79\% similar) at the amino acid level with the product of the E. coli $\operatorname{sbm} A$ gene (Fig. 8). Mutations in $\operatorname{sbm} A$ result in resistance to microcin B17, a peptide antibiotic (Lavina et al. 1986). The resistance is probably attributable to failure of the mutants to transport microcin B17 into the cytoplasm, as they are sensitive to endogenously expressed microcin B17 (Lavina et al. 1986).
The Kyte-Doolittle hydrophobicity profiles of BacA and SbmA are virtually superimposable, suggesting that the two proteins take up similar conformations (Fig. 9). The putative cytoplasmic stretches are more conserved $198 /$ $126 ; 78 \%$ identity, compared with $64 \%$ identity overall) than are the other regions of BacA and SbmA (see Fig. 7). This may be an indication that the cytoplasmic loops perform a function that is conserved between the two proteins.

Some transport proteins include amphipathic transmembrane helices that form a channel; therefore, we examined the BacA sequence for amphipathic helices using the hydrophobic moment criterion (Eisenberg et al. 1984). None of the putative transmembrane helices have a hydrophobic moment high enough to suggest that they are amphipathic. The fifth and seventh putative helices of BacA contain proline residues, which are conserved in the SbmA sequence. Although proline residues are rare in $\alpha$-helices, they occur with relatively high frequency in the transmembrane helices of transport and receptor proteins, where they may play structural roles in bending the helices or function in allowing the helices to flex through cis-trans isomerization about X-Pro peptide bonds (Williams and Deber 1991). Considered as a whole, the analysis of the $b a c A$ sequence provides a strong indication that $\mathrm{BacA}$ is a transmembrane protein that functions in the transport of molecules, possibly peptides, across the inner membrane of $R$. meliloti.
Figure 7. A model of the topology of BacA in the inner membrane. The amino terminus is drawn at lower left, and the carboxyl terminus at upper right. Boxed regions indicate membrane-spanning segments based on Klein predictions /Peripheral/integral odds for segments between amino acid numbers: $9-29,1.43 \mathrm{e}^{-2} ; 60$ $78,1.19 \mathrm{e}^{-1} ; 96-112,4.27 \mathrm{e}^{-1} ; 138-168$, $9.06 \mathrm{e}^{-4} ; \quad 208-231, \quad 1.62 \mathrm{e}^{-3} ; 245-269$, $9.35 \mathrm{e}^{-3}$; and $339-357,2.37 \mathrm{e}^{-2} \%$. Segments drawn above the boxed regions are proposed to be periplasmic; those drawn below are proposed to be cytoplasmic. Residues that are circled are identical in BacA and SbmA.

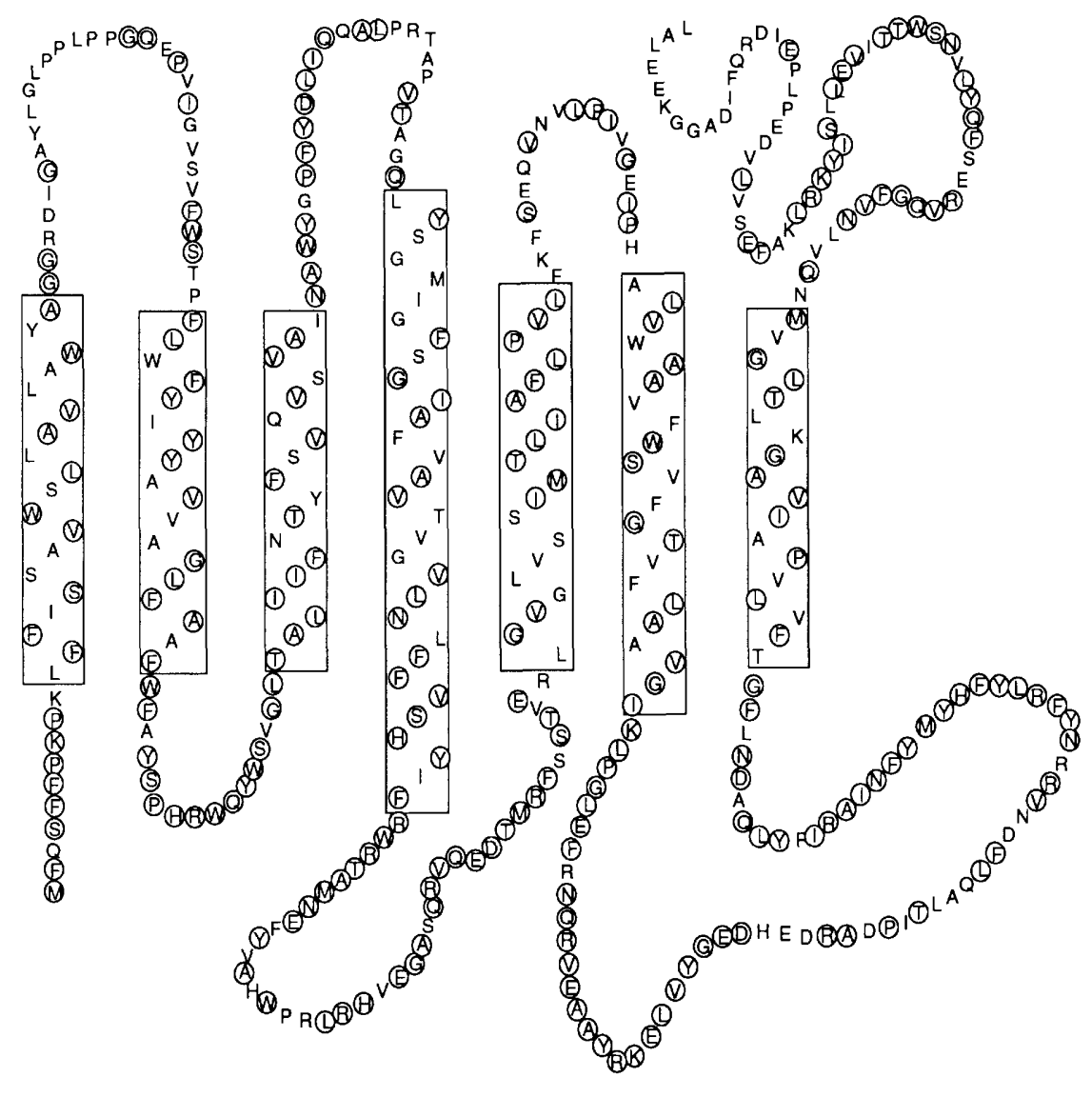




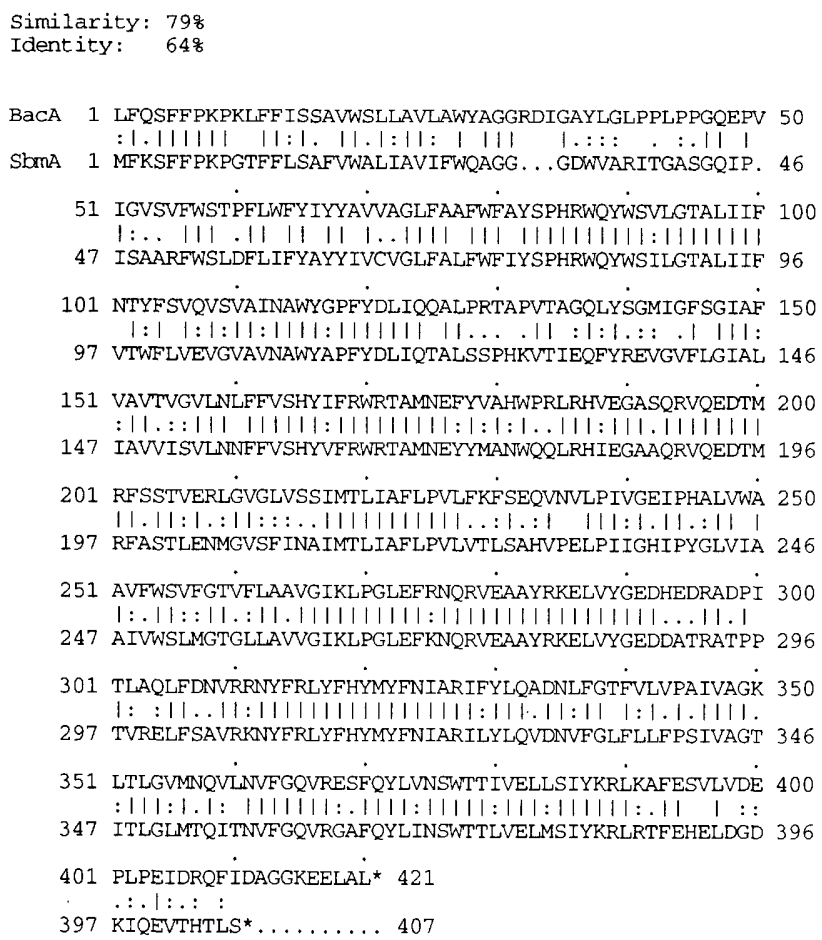

Figure 8. Alignment of BacA and the $E$. coli protein SbmA. The two proteins are $64 \%$ identical and $79 \%$ similar. Lines indicate identical residues, double dots indicate conservative substitutions, and single dots indicate less conservative substitutions.

\section{$B a c A / S b m A$ is broadly conserved among Gram-negative prokaryotes}

The high degree of conservation between BacA and SbmA was somewhat surprising, because among Gramnegative bacteria, $R$. meliloti and E. coli are only dis-

\section{$\mathrm{BacA}$}

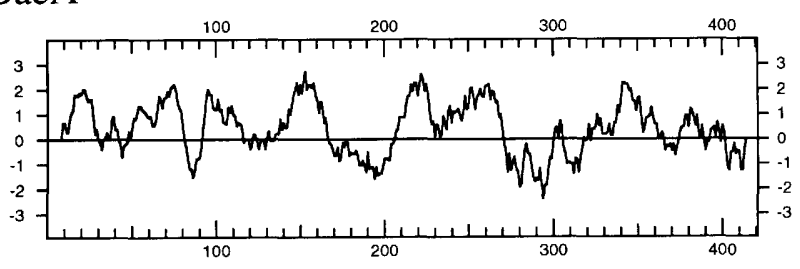

\section{SbmA}

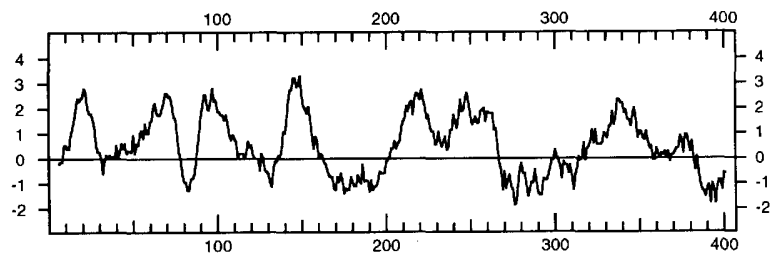

Figure 9. Kyte-Doolittle (Kyte and Doolittle 1982) hydropathy plots of BacA and SbmA. Positive values indicate increasing hydrophobicity. A window of 11 amino acids was used for the scan. tantly related. This led us to examine whether other bacteria also have $b a c A$ homologous sequences. A $b a c A$ probe hybridized to DNA from many Gram-negative bacteria (Fig. 10) and from the Gram-positive bacterium Streptomyces phaechromogenes (data not shown), under conditions of high stringency. We were unable to detect bacA homologous sequences in Pseudomonas syringae, Legionella pneumophila, Bacillus subtilis, or Brevibacterium luteum at high or low stringency. The conservation of $b a c A$ homologous sequences among distantly related species of bacteria suggests that these genes must confer a selective advantage on bacteria living in a variety of environments.

\section{Discussion}

We have shown that the symbiotic deficiency of $R$. meliloti bacA mutants results in the arrest of nodule development at the onset of bacteroid differentiation. Our observations indicated that as with wild-type bacteria, these mutants invade nodules through infection threads and are released from the tips of the infection threads

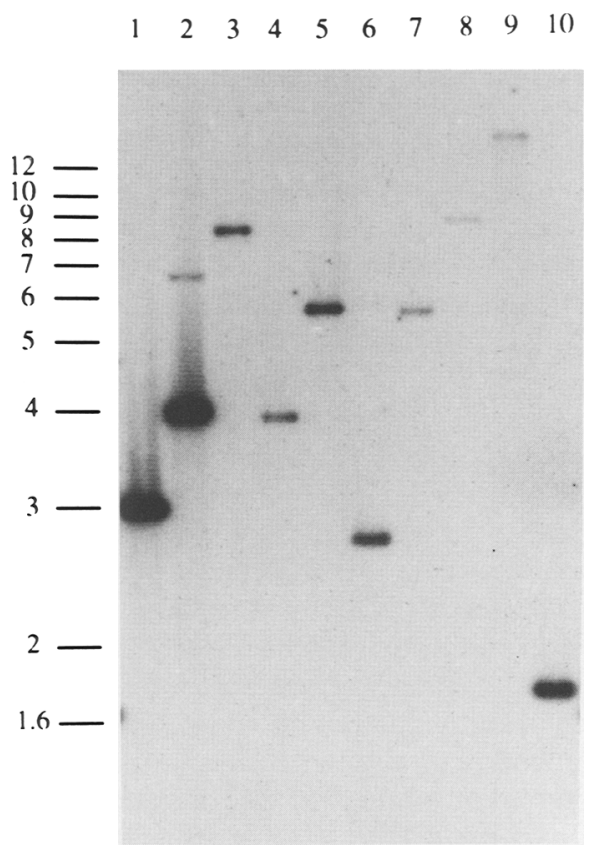

Figure 10. Hybridization of a ${ }^{32} \mathrm{P}$-labeled probe corresponding to the bacA sequence between residues 626 and 982 with various genomic DNA samples. (Lane 1) R. meliloti strain Rm8002 digested with BamHI; (lane 2) $R$. meliloti strain Rm8386 (bacA386::TnphoA) digested with BamHI; (lane 3) E. coli digested with HindIII; (lane 4) Rhizobium leguminosarum digested with HindIII; (lane 5) A. tumefaciens digested with HindIII; (lane 6) Citrobacter freundii digested with PstI; (lane 7) Salmonella typhimurium digested with EcoRI; (lane 8) S. typhimurium digested with PstI; (lane 9) Shigella flexneri digested with PstI; (lane 10) Klebsiella pneumoniae digested with PstI. Hybridization of this probe to sequences present in Alcaligenes eutrophus, Streptomyces phaechromogenes, and Nocardia atidiscavarium was also observed (data not shown). 
into the plant cell cytoplasm. Unlike wild-type bacteroids, which ultimately differentiate into nitrogen-fixing type IV bacteroids, bacA bacteroids undergo senescence before reaching the type II bacteroid stage. Many of the senescent $b a c A$ bacteroids contained poly- $\beta$-hydroxybutyrate granules within their cytoplasm, suggesting that senescence occurs before the onset of bacteroid differentiation, as loss of these granules is the first observable step in differentiation of wild-type bacteroids (Paau et al. 1980; Hirsch et al. 1982). These phenotypes placed the developmental block of bacA mutants at a stage after release of bacteria from infection threads and before the beginning of bacteroid differentiation.

Thus, our cytological studies have placed the $b a c A$ developmental block later than those of hemA mutants, which are not released from infection threads, as well as exo and $n d v$ mutants, which fail to invade nodules. Studies of the expression of nodulins, host proteins found specifically in nodules, have shown that the development of the plant cells in bacA nodules also proceeds to a later stage than it does in hemA, exo, or $n d v$ nodules. Only one nodulin, Nms30, has been detected in hemA, exo, or $n d v$ nodules (Dickstein et al. 1988, 1991; Norris et al. 1988; VandeWiel et al. 1990). In contrast, two late nodulins, Nms22 and leghemoglobin, were found in bacA nodules (Allen et al. 1992). Other late nodulins may also be expressed in these nodules. This result suggests that there is a dramatic shift in the patterns of host cell gene expression between the stages of nodule invasion by bacteria within infection threads and the beginning of bacteroid development.

Our studies on the in plarta expression of $b a c A$ revealed that $b a c A$ is strongly expressed in nodules. We estimated that the region of most intense staining includes proximal zone II, zoneII-III interzone, and distal zone III, regions of the nodule where bacteroid differentiation occurs. This pattern is consistent with our conclusion that $b a c A$ is required for bacteroid differentiation. We also observed that the expression of a $b a c A-$ phoA fusion was at least as strong as that of a $d c t A-$ pho $A$ fusion, as judged by the time required for histochemical staining to occur. This observation, which suggests that the expression of $b a c A$ in developing nodules is comparable with the expression of a gene known to encode a protein with an essential mechanistic role in bacteroid physiology $(d c t A)$, may be an indication that $b a c A$ encodes a protein with a mechanistic, rather than a regulatory, furction. The less intense expression of $b a c A$ in the symbiotic zone may be the result of a requirement for $b a c A$ in mature bacteroids or may simply reflect a basal level of expression.

Sequencing of $\mathrm{bacA}^{+}$revealed that the presumptive BacA protein is highly homologous to the $E$. coli protein SbmA. The Kyte-Doolittle hydropathy plots of the two proteins are also very similar, and the Klein algorithm predicts that each protein contains seven transmembrane domains. The SbmA protein was identified in $E$. coli as a consequence of the fact that $\operatorname{sbm} A$ mutants are resistant to microcin $\mathrm{B} 17$, a peptide antibiotic. $s b m A$ mutants remain sensitive to endogenously expressed mi- crocin $B 17$, suggesting that resistance results from failure to transport microcin B17 into the cytoplasm (Lavina et al. 1986). Therefore, we interpret the homology between BacA and SbmA as an indication that BacA is a transport protein, perhaps a peptide transport protein.

We were able to detect sequences highly homologous to BacA in a variety of other bacteria by high-stringency Southern hybridization. This conservation among BacA homologs indicates that these proteins confer a selective advantage on many dissimilar bacteria. Most of these species do not undergo bacteroid development; therefore, SbmA/BacA must have an important function in free-living cells. Although their normal physiological function is not yet understood, obviously it cannot be the uptake of toxic peptides. In light of the requirement for BacA in bacteroid development, it would be interesting to determine if its homologs are required for pathogenicity in bacteria that invade eukaryotic cells.

Any hypothesis for the role of BacA in nodule development should explain the principal results from this work: (1) bacA mutants fail to undergo normal bacteroid development, undergoing senescence shortly after their release from infection threads; (2) in effective nodules, bacA is strongly expressed in nodule regions where bacteroid development occurs, apparently at levels comparable with that of an essential metabolic gene; (3) BacA is homologous to an E. coli protein involved in transport; and (4) bacA is strongly conserved among a variety of Gram-negative bacteria. One possibility is that the physiological role of BacA is to transport peptides or small proteins. Uptake of a specific peptide or short protein could serve to signal the bacterium to begin bacteroid development. Just as uptake of microcin B17 through an SbmA-mediated process inhibits DNA replication in $E$. coli, uptake of a plant-derived peptide or small protein could play a role in altering cellular functions in $R$. meliloti, leading to bacteroid development. A precedent for the idea of peptides produced by plants having signaling functions is provided by the observation that an 18amino-acid peptide called systemin is produced by plants in response to wounding and functions to induce expression of genes associated with resistance to insect attack (Pearce et al. 1991). In this model for BacA function, the conservation of BacA/SbmA could be explained if BacA/ SbmA homologs serve to transport peptides for other purposes in nonsymbiotic bacteria, such as use for carbon or nitrogen sources, or both.

Another possibility is that the physiological role of BacA is to import a molecule that is not a peptide or short protein. The specificity of SbmA is not known, but microcin $\mathrm{B} 17$ is a highly modified peptide (Yorgey et al. 1992); therefore, it is certainly possible that BacA/SbmA recognize nonpeptide compounds as substrates for transport. Such a nonprotein molecule could serve as a physiological marker that allows the bacteria to sense their position within the developing nodule and respond appropriately. Alternatively, the bacteria may face a sudden shift in environmental conditions, such as $\mathrm{pH}$, electrolyte concentration, or osmotic strength, upon their release from the infection thread into the plant cell cy- 
toplasm. BacA might then be required for transport of a molecule that allows the bacteria to adjust to this shock. Perhaps modifications of the contents of the cytoplasm or periplasmic space are necessary for the bacteria to adjust to their new milieu and complete their differentiation into bacteroids. In this model the conservation of BacA/SbmA could be explained by postulating that it is also important in allowing free-living bacteria to adjust to changes in their environment.

\section{Materials and methods}

Strains, plasmids, and media

All R. meliloti strains were derivatives of Rml021 (Meade et al. 1982). These were Rm8002 (pho-1), Rm8386 (pho-1, bacA386::TnphoA, formerly fix-386::TnphoAl, and Rm8384 (pho-1, dctA384::TnphoA) (Long et al. 1988a). Plasmid pRK600 provides transfer functions in triparental matings (Finan et al. 1986), and pRmT8 complements dctA384::TnphoA (Finan et al. 1986; Yarosch et al. 1989). Bacteria were grown in LB medium (Maniatis et al. 1982), with $2.5 \mathrm{~mm} \mathrm{MgSO}_{4}$ and $2.5 \mathrm{mM} \mathrm{CaCl}_{2}$ added for $R$. meliloti. Antibiotics were used at the following concentrations: neomycin $(\mathrm{Nm}), 200 \mu \mathrm{g} / \mathrm{ml}$; gentamycin $(\mathrm{Gm})$, $20 \mu \mathrm{g} / \mathrm{ml}$; spectinomycin $(\mathrm{Sp}), 50 \mu \mathrm{g} / \mathrm{ml}$; streptomycin $(\mathrm{Sm})$, $400 \mu \mathrm{g} / \mathrm{ml}$; tetracycline $(\mathrm{Tc}), 10 \mu \mathrm{g} / \mathrm{ml}$, kanamycin $(\mathrm{Km}), 25$ $\mu \mathrm{g} / \mathrm{ml}$; and chloramphenicol $(\mathrm{Cm}), 10 \mu \mathrm{g} / \mathrm{ml}$.

\section{Genetic techniques}

Generalized transduction using $\Phi \mathrm{M} 12$ was performed as described (Finan et al. 1984). Conjugal transfer of plasmids into $R$. meliloti strains was done in triparental matings using pRK600 to provide transfer functions (Leigh et al. 1985). Tn3Gus was obtained from B. Staskawicz (University of California, Berkeley), and insertions of Tn3Gus in pJG50 were isolated by the method of Stachel et al. (1985). Insertions were recombined into the genome by homogenotization as described by Leigh et al. (1985).

\section{Nodulation tests}

Medicago sativa cv. Iroquois was obtained from Agway, Inc. (Plymouth, IN). Plants were grown and inoculated as described previously (Leigh et al. 1985). The existence of pink cylindrical nodules on the roots of healthy green plants was taken as evidence that nitrogen fixation was occurring. Plants with ineffective nodules were blanched and stunted.

\section{Light and electron microscopy}

Nodules were excised from plant roots, fixed, postfixed with $\mathrm{OsO}_{4}$, and embedded in Spurr's low-viscosity embedding medium (Spurr 1969) (Polysciences, Warrington, PA) as described by Hirsch et al. (1983). For light microscopy, longitudinal sections were cut $500 \mathrm{~nm}$ thick and stained with Multiple Stain Solution (Polysciences, Warrington, PA). For electron microscopy, sections were cut $90 \mathrm{~nm}$ thick, and stained with uranyl acetate and lead citrate, as described (Hirsch et al. 1983).

\section{Histochemical staining}

Nodules were excised from roots 19 days postinoculation and processed as described (Reuber et al. 1991). Sections of Rm8002and $\mathrm{Rm} 8384 / \mathrm{pRmT} 8$-induced nodules were stained overnight at $37^{\circ} \mathrm{C}$, whereas $\mathrm{Rm} 8386 / \mathrm{pJG} 50$-induced nodules were stained for $6 \mathrm{hr}$ at $37^{\circ} \mathrm{C}$. We found that fixed nodules could be stored at $4^{\circ} \mathrm{C}$ for as long as 8 weeks before sectioning and staining without appreciable loss of alkaline phosphatase activity.

\section{DNA manipulations}

Plasmid DNA was isolated from overnight cultures of $E$. coli by the alkaline lysis method (Maniatis et al. 1982). R. meliloti genomic DNA was prepared by the method of Marmur (1961). Restriction enzymes and DNA ligase were used according to the instructions of the supplier (New England Biolabs, Beverly, MA). Southern analysis was performed on GeneScreen Plus membranes (New England Nuclear, Boston, MA), with nicktranslated probes made using a nick-translation kit (Bethesda Research Laboratories, Gaithersburg, MD|, or by PCR.

\section{Isolation of $\mathrm{bacA}^{+}$cosmids}

Southern hybridization was used to determine that a $6.5-\mathrm{kb}$ BamHI fragment of Rm8386 genomic DNA contained the kanamycin resistance gene of $\mathrm{Tn} p h o A$ and genomic sequences flanking one side of the insertion (Fig. 4). BamHI fragments in this size range were isolated from a digest of Rm8386 DNA and ligated into the broad host range vector pRK404 (Ditta et al. 1985). A plasmid containing the correct fragment was obtained by selection for kanamycin resistance and designated pJG386. A 2.4-kb BamHI-EcoRI restriction fragment that contained $1.7 \mathrm{~kb}$ of $R$. meliloti sequences flanking the TnphoA transposon was isolated from pJG386 and used to probe a genomic library of $R$. meliloti DNA cloned into the cosmid pLAFR1 (Friedman et al. 1982) by colony hybridization (Maniatis et al. 1982).

\section{Sequencing}

The 3.0-kb BamHI fragment of pJG51 was cloned into the Bluescript SK + vector (Stratagene, La Jolla, CA). To allow sequencing of both strands, two sets of unidirectional deletion series were constructed using exonucleases III and VII, according to the instructions of the supplier /U.S. Biochemical, Cleveland, $\mathrm{OH})$. The resulting deletion plasmids were sequenced by the Sanger dideoxy chain termination method using a Sequenase kit (U.S. Biochemical, Cleveland, OH). The position of the bacA386::TnphoA fusion joint was determined by sequencing pJG386 using a primer homologous to TnphoA. This information defined the correct reading frame of the bacA gene.

Hydrophobicity was plotted by the method of Kyte and Doolittle (1982), using DNA Strider software (C. Marck and Commissariat de l'Energie Atomique, France). Data bases were searched using the BLAST network service of the National Center for Biotechnology Information (Altschul et al. 1990). All other sequence analyses were performed with the University of Wisconsin GCG sequence analysis package (Devereux et al. 1984).

\section{Acknowledgments}

We thank Pat Reilly for assistance with light and electron microscopy, Ann Hirsch, Harvey Lodish, Dan Sheirer, and Georges Truchet for helpful advice and discussions, and Rebecca Dickstein and Kathy Dunn for communicating results before publication. We also thank Sam Miller, Mark Krebs, Oliver Peoples, Ellen Guthrie, Laurance Rahme, and Roy Magnuson for gifts of DNA samples from various bacteria. This work was supported by U.S. Public Health Service grant GM31030 to G.C.W. I.G. was supported in part by a National Science Foundation predoc- 
toral fellowship and in part by the Biotechnology Training Grant administered by the M.I.T. Department of Biology.

The publication costs of this article were defrayed in part by payment of page charges. This article must therefore be hereby marked "advertisement" in accordance with 18 USC section 1734 solely to indicate this fact.

\section{Note added in proof}

The nucleotide sequence data reported in this paper have been submitted to the EMBL data library under accession number X73522.

\section{References}

Allen, T., S. Raja, G. Ganter, and K. Dunn. 1992. Sequential expression of two late nodulin genes in the infected cells of alfalfa root nodules. Mol. Plant-Microbe Int. 5: 430-434.

Altschul, S.F., W. Gish, W. Miller, E.W. Meyers, and D.J. Lipmann. 1990. A basic local alignment search tool. J. Mol. Biol. 215: 403-410.

Benson, S.A., M.N. Hall, and T.J. Silhavy. 1985. Genetic analysis of protein export in Escherichia coli K12. Annu. Rev. Biochem. 54: 101-134.

Bolton, E., B. Higgisson, A. Harrington, and F. O'Gara. 1986. Dicarboxylic acid transport in Rhizobium meliloti: Isolation of mutants and cloning of dicarboxylic acid transport genes. Arch. Microbiol. 144: 142-146.

Charles, T.C. and T.F. Finan. 1990. Genetic map of Rhizobium meliloti megaplasmid pRmeSU47b. I. Bacteriol. 172: 24692476.

Charles, T.C., W. Newcomb, and T.M. Finan. 1991. ndvF, a novel locus located on megaplasmid pRmeSU47b (pEXO) of Rhizobium meliloti, is required for normal nodule development. J. Bacteriol. 173: 3981-3992.

Devereux, J., P. Haeberli, and O. Smithies. 1984. A comprehensive set of sequence analysis programs for the VAX. Nucleic Acids Res. 12: 387-395.

Dickstein, R., T. Bisseling, V.N. Reinhold, and F.M. Ausubel. 1988. Expression of nodule-specific genes in alfalfa root nodules blocked at an early stage of development. Genes $\&$ Dev. 2: 677-687.

Dickstein, R., D.C. Scheirer, W.H. Fowle, and F.M. Ausubel. 1991. Nodules elicited by Rhizobium meliloti heme mutants are arrested at an early stage of development. Mol. Gen. Genet. 230: 423-432.

Ditta, G., T. Schmidhauser, E. Yakobson, P. Lu, X.-W. Liang, D.R. Finlay, D. Guiney, and D.R. Helinski. 1985. Plasmids related to the broad host range vector, pRK290, useful for gene cloning and for monitoring gene expression. Plasmid 13: 149-153.

Dylan, T., L. Ielpi, S. Stanfield, L. Kashyap, C. Douglas, M. Yanofsky, E. Nester, D.R. Helinski, and G. Ditta. 1986. Rhizobium meliloti genes required for nodule development are related to chromosomal virulence genes in Agrobacterium tumefaciens. Proc. Natl. Acad. Sci. 83: 4403-4407.

Eisenberg, D., R.M. Sweet, and T.C. Terwilliger. 1984. The hydrophobic moment detects periodicity in protein hydrophobicity. Proc. Natl. Acad. Sci. 81: 140-144.

Finan, T.M., E.K. Hartwieg, K. LeMieux, K. Bergman, G.C. Walker, and E.R. Signer. 1984. General transduction in Rhizobium meliloti. J. Bacteriol. 159: 120-124.

Finan, T.M., A.M. Hirsch, J.A. Leigh, E. Johansen, G.A. Kuldau, S. Deegan, G.C. Walker, and E.R. Signer. 1985. Symbiotic mutants of Rhizobium meliloti that uncouple plant from bacterial differentiation. Cell 40: 869-877.
Finan, T.M., B. Kunkel, G.F. de Vos, and E.R. Signer. 1986. A second symbiotic megaplasmid in Rhizobium meliloti carrying exopolysaccharide and thiamine synthesis genes. $I$. Bacteriol. 167: 66-72.

Fisher, R.F. and S.R. Long. 1992. Rhizobium-Plant signal exchange. Nature 357: 655-660.

Friedman, A.M., S.R. Long, S.E. Brown, W.J. Biukema, and F.M. Ausubel. 1982. Construction of a broad host range cosmid cloning vector and its use in the genetic analysis of Rhizobium mutants. Gene 18: 289-296.

Geremia, R.A., S. Cavaignac, A. Zorreguieta, N. Toro, J. Olivares, and R.A. Ugalde. 1987. A Rhizobium meliloti mutant that forms ineffective pseudonodules in alfalfa produces exopolysaccharide but fails to form $\beta-(1,2)$ glucan. I. Bacteriol. 169: 880-884.

Glazebrook, J. and G.C. Walker. 1989. A novel exopolysaccharide can function in place of the Calcofluor-binding exopolysaccharide in nodulation of alfalfa by Rhizobium meliloti. Cell 56: 661-672.

-1991. Genetic techniques in Rhizobium meliloti. Methods Enzymol. 204: 398-418.

Gold, L. and G. Stormo. 1987. Translational initiation. In Escherichia coli and Salmonella typhimurium. Cellular and molecular biology (ed. Frederick C. Neidhardt), Vol. II, pp. 1302-1307. American Society for Microbiology, Washington D.C.

Gren, E.J. 1984. Recognition of messenger RNA during translational initiation in Escherichia coli. Biochimie 66: 1-29.

Hirsch, A.M., S.R. Long, M. Bang, N. Haskins, and F.M. Ausubel. 1982. Structural studies of alfalfa roots infected with nodulation mutants of Rhizobium meliloti. I. Bacteriol. 151: $411-419$.

Hirsch, A.M., M. Bang, and F.M. Ausubel. 1983. Ultrastructural analysis of ineffective alfalfa nodules formed by nif::Tn5 mutants of Rhizobium meliloti. I. Bacteriol. 155: 367-380.

Jordan, D.C., I. Grinyer, and W.H. Coulter. 1963. Electron microscopy of infection threads and bacteria in young root nodules of Medicago sativa. J. Bacteriol. 86: 125-137.

Keller, M., P. Müller, R. Simon, and A. Pühler. 1988. Rhizobium meliloti genes for exopolysaccharide synthesis and nodule infection located on megaplasmid 2 are actively transcribed during symbiosis. Mol. Plant-Microbe Int. 1: 267-274.

Klein, P., M. Kanehisa, and C. DeLisi. 1985. The detection and classification of membrane-spanning proteins. Biochem. et Biophys. Acta 815: 468-476.

Kyte, J. and R.F. Doolittle. 1982. A simple method for displaying the hydropathic character of a protein. J. Mol. Biol. 157: 105132.

Lavina, M., A.P. Pugsley, and F. Moreno. 1986. Identification, mapping, cloning and characterization of a gene $(\mathrm{sbmA})$ required for microcin B17 action on Escherichia coli K12. $/$. Gen. Microbiol. 132: 1685-1693.

Leigh, J.A., E.R. Signer, and G.C. Walker. 1985. Exopolysaccharide-deficient mutants of $R$. meliloti that form ineffective nodules. Proc. Natl. Acad. Sci. 82: 6231-6235.

Leigh, J.A., J.W. Reed, J.F. Hanks, A.M. Hirsch, and G.C. Walker. 1987. Rhizobium meliloti mutants that fail to succinylate their Calcofluor-binding exopolysaccharide are defective in nodule invasion. Cell 51: 579-587.

Long, S.R. 1989a. Rhizobium genetics. Annu. Rev. Genet. 23: 483-506.

- 1989b. Rhizobium-legume nodulation: Life together in the underground. Cell 56: 203-214.

Long, S., S. McCune, and G.C. Walker. 1988a. Symbiotic loci of Rhizobium meliloti identified by random TnphoA mutagenesis. J. Bacteriol. 170: 4257-4265. 
Long, S., J.W. Reed, J. Himawan, and G.C. Walker. 1988b. Genetic analysis of a cluster of genes required for synthesis of the Calcofluor-binding exopolysaccharide of Rhizobium meliloti. J. Bacteriol. 170: 4239-4248.

Maniatis, T., E.F. Fritsch, and J. Sambrook. 1982. Molecular cloning: A laboratory manual. Cold Spring Harbor Laboratory, Cold Spring Harbor, New York.

Manoil, C. and J. Beckwith. 1985. TnphoA: A transposon probe for protein export signals. Proc. Natl. Acad. Sci. 82: 81298133.

Marmur, J. 1961. A procedure for the isolation of deoxyribonucleic acid from micro-organisms. I. Mol. Biol. 3: 208-218.

Meade, H.M., S.R. Long, G.B. Ruvkun, S.E. Brown, and F.M. Ausubel. 1982. Physical and genetic characterization of symbiotic and auxotrophic mutants of Rhizobium meliloti induced by transposon Tn5 mutagenesis. I. Bacteriol. 149: 114-122.

Newcomb, W. 1981. Nodule morphogenesis and differentiation. Int. Rev. Cytol. Suppl. 13: 247-298.

Norris, J.H., L.A. Macol, and A.M. Hirsch. 1988. Nodulin gene expression in effective alfalfa nodules and in nodules arrested at three different stages of development. Plant Physiol. 88: 321-328.

Paau, A.S., J.R. Cowles, and D. Raveed. 1978. Development of bacteroids in alfalfa (Medicago sativa) nodules. Plant Physiol. 62: 526-530.

Paau, A.S., C.B. Bloch, and W.J. Brill. 1980. Developmental fate of Rhizobium meliloti bacteroids in alfalfa nodules. $J$. Bacteriol. 143: 1480-1490.

Pankhurst, C.E. 1974. Ineffective Rhizobium trifolii mutants examined by immune-diffusion, gel electrophoresis and electron microscopy. J. Gen. Microbiol. 82: 405-413.

Patel, J.J. and A.F. Yang. 1981. Light and electron microscopic studies of nodule structure of alfalfa. Can. I. Microbiol. 27: 36-43.

Pazour, G.J. and A. Das. 1990. virG, an Agrobacterium tumefaciens transcriptional activator, initiates translation at a UUG codon and is a sequence-specific DNA-binding protein. J. Bacteriol. 172: 1241-1249.

Pearce, G., D. Strydom, S. Johnson, and C.A. Ryan. 1991. A polypeptide from tomato leaves induces wound-inducible proteinase inhibitor proteins. Science 253: $895-898$.

Reed, J.W. and G.C. Walker. 1991. Acidic conditions permit effective nodulation of alfalfa by invasion-deficient Rhizobium meliloti exoD mutants. Genes \& Dev. 5: 2274-2287.

Reuber, T.L., S. Long, and G.C. Walker. 1991. Regulation of Rhizobium meliloti exo genes in free-living cells and in planta examined using TnphoA fusions. I. Bacteriol. 173: 426-434.

Rolfe, B.G. and P.M. Gresshoff. 1988. Genetic analysis of legume nodule initiation. Annu. Rev. Plant Physiol. Plant Mol. Biol. 39: 297-319.

Spurr, A.R. 1969. A low viscosity epoxy resin embedding medium for electron microscopy. J. Ultrastruct. Res. 26: 21-43.

Stachel, S.E., G. An, C. Flores, and E.W. Nester. 1985. A $\operatorname{Tn} 31 a c Z$ transposon for the random generation of $\beta$-galactosidase gene fusions: Application to the analysis of gene expression in Agrobacterium. EMBO I. 4: 891-898.

Truchet, G., M. Michel, and J. Denarie. 1980. Sequential analysis of the organogenesis of lucerne (Medicago sativa) root nodules using symbiotically-defective mutants of Rhizobium meliloti. Differentiation 16: 163-172.

$\mathrm{Tu}$, J.C. 1977. Structural organization of the rhizobial root nodule of alfalfa. Can. J. Bot. 55: 35-43.

Van de Wiel, C., J.H. Norris, B. Bochenek, R. Dickstein, T. Bisseling, and A.M. Hirsch. 1990. Nodulin gene expression and
ENOD2 localization in effective, nitrogen-fixing and ineffective, bacteria-free nodules of alfalfa. Plant Cell 2: 10091017.

Vasse, J., F. deBilly, S. Camut, and G. Truchet. 1990. Correlation between ultrastructural differentiation of bacteroids and nitrogen fixation in alfalfa nodules. J. Bacteriol. 172: 42954306.

von Heijne, G. 1984. Analysis of the distribution of charged residues in the $\mathrm{N}$-terminal region of signal sequences: Implications for protein export in prokaryotic and eukaryotic cells. EMBO I. 3: 2315-2318.

von Heijne, G. and Y. Gavel. 1988. Topogenic signals in integral membrane proteins. Eur. J. Biochem. 174: 671-678.

Werner, D., E. Morschel, R. Stripf, and B. Winchenbach. 1980. Development of nodules of Glycine max infected with an ineffective strain of Rhizobium japonicum. Planta 147: 320-329.

Williams, K.A. and C.M. Deber. 1991. Proline residues in transmembrane helices: Structural or dynamic role? Biochemistry 30: 8919-8923.

Wolfe, P.B., W. Wickner, and J.M. Goodman. 1983. Sequence of the leader peptidase gene of Escherichia coli and the orientation of leader peptidase in the bacterial envelope. I. Biol. Chem. 258: 12073-12080.

Yarosch, O.K., T.C. Charles, and T.M. Finan. 1989. Analysis of $\mathrm{C}_{4}$-dicarboxylate transport genes in Rhizobium meliloti. Mol. Microbiol. 3: 813-823.

Yorgey, P., J. Lee, and R. Kolter. 1992. The structure and maturation pathway of microcin B17. In NATO ASI Series, Series H: Cell biology (ed. R. Jones, C. Lazdunski, and F. Pattus), Vol. 65, pp. 19-31. Springer-Verlag, Heidelberg, Germany. 


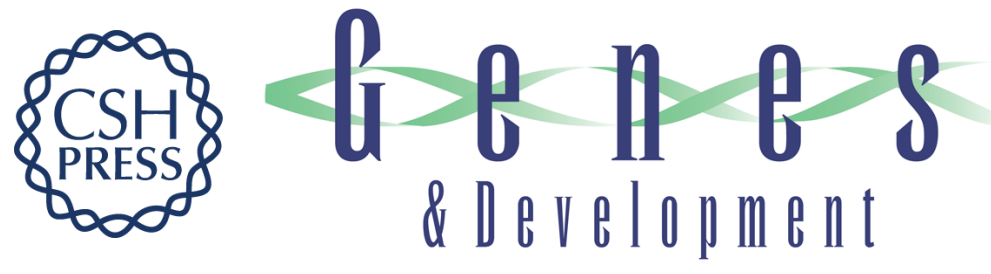

\section{A Rhizobium meliloti homolog of the Escherichia coli peptide-antibiotic transport protein SbmA is essential for bacteroid development.}

J Glazebrook, A Ichige and G C Walker

Genes Dev. 1993, 7:

Access the most recent version at doi:10.1101/gad.7.8.1485

References This article cites 60 articles, 26 of which can be accessed free at: http://genesdev.cshlp.org/content/7/8/1485.full.html\#ref-list-1

License

Email Alerting Service

Receive free email alerts when new articles cite this article - sign up in the box at the top right corner of the article or click here.

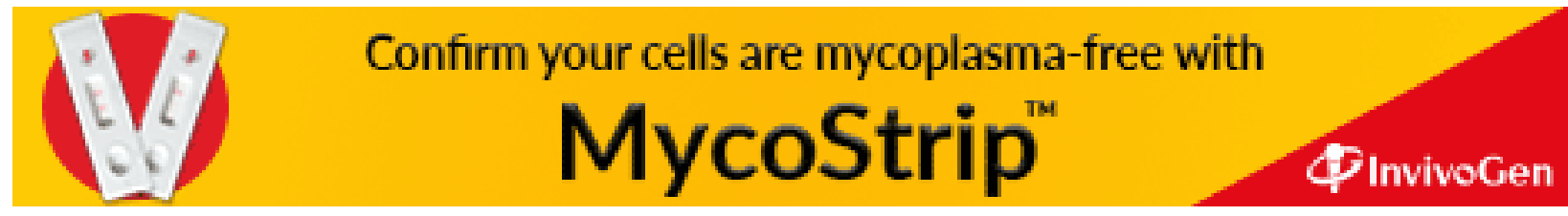

